\title{
Cardiac retransplantation in childhood: Analysis of data from the United Network for Organ Sharing
}

William T. Mahle, MD, ${ }^{a, b}$ Robert N. Vincent, $M D^{a, b}$ and Kirk R. Kanter, $M^{c}$

From the Sibley Heart Center Cardiology, Children's Healthcare of Atlanta, ${ }^{a}$ and the Department of Pediatrics, ${ }^{\text {b and Department }}$ of Surgery, Division of Cardiothoracic Surgery, ${ }^{\mathrm{c}}$ Emory University School of Medicine, Atlanta, Ga.

Supported in part by Health Resources and Services Administration contract 231-000115 . The content is the responsibility of the authors alone and does not necessarily reflect the views or policies of the Department of Health and Human Services, nor does mention of trade names, commercial products, or organizations imply endorsement by the US Government.

Received for publication Dec 22, 2004; revisions received Feb 10, 2005; accepted for publication Feb 25, 2005.

Address for reprints: William T. Mahle, MD, Children's Healthcare of Atlanta, Emory University School of Medicine, 1405 Clifton Rd, NE, Atlanta, GA 30322-1062 (E-mail: wmahle@emory.edu).

J Thorac Cardiovasc Surg 2005;130:542-6

$0022-5223 / \$ 30.00$

Copyright () 2005 by The American Association for Thoracic Surgery

doi:10.1016/j.jtcvs.2005.02.050
Objective: For children in whom graft failure develops after cardiac transplantation, retransplantation is often considered. Although some centers have reported equivalent results for retransplantation as for primary transplantation, this strategy remains controversial. We sought to examine outcomes after retransplantation in children and to identify risk factors for mortality.

Methods: United Network for Organ Sharing records of heart transplantation for subjects younger than 18 years from 1987 to 2004 were reviewed. Indications for retransplantation and patient characteristics were evaluated. Analysis was performed with proportional hazards regression, controlling for other potential risk factors.

Results: Among the 4227 pediatric heart transplants, there were 219 retransplants. The most common indication for retransplantation was coronary allograft vasculopathy $(51 \%)$. The mean interval from initial heart transplant to retransplantation was $4.7 \pm 3.8$ years. Forty-two retransplants (19\%) were performed within 180 days of primary transplantation. Survivals at 1,5 , and 10 years after retransplantation were $79 \%, 53 \%$, and $44 \%$, respectively. In multivariate analysis, retransplantation was associated with significantly higher mortality than primary transplantation (odds ratio 1.67, 95\% confidence interval 1.32-2.12, $P<.001$ ). Patients who underwent retransplantation within 180 days of primary transplantation had a significantly lower 1-year survival than did other retransplant recipients $(53 \%$ vs $86 \%$, respectively, $P<.02$ ). Subjects who required mechanical ventilation before retransplantation also had poorer survival $(P<.03)$.

Conclusion: Survival after cardiac retransplantation in children is inferior to that after primary transplantation. Although results are acceptable, the impact of retransplantation on the availability of donor hearts requires further consideration.

$\mathrm{H}$ eart transplantation plays an important role in the management of children with congenital heart disease and cardiomyopathies. The outcome after pediatric heart transplantation has improved dramatically during the past 20 years, and survival is superior to that reported for adult transplantation. ${ }^{1-2}$ Nonetheless, graft failure occurs in a significant number of children, and the survival half-life in children after heart transplantation is just greater than 12 years. ${ }^{1}$ Many centers routinely undertake retransplantation for those children with graft failure. Some single-center reports have suggested that survival after retransplantation is equivalent to that after primary transplantation. ${ }^{3-5}$ Data from adults, however, suggest that retransplantation is associated with significantly poorer outcome than primary transplantation, with fewer than $40 \%$ of subjects surviving to 5 years. ${ }^{6-7}$ In this study we examined the data from the United Network for Organ Sharing (UNOS) to analyze the outcome and risk factors for children who undergo retransplantation. 
TABLE 1. Variables analyzed for association with survival

\begin{tabular}{lll}
\hline Donor & \multicolumn{1}{c}{ Recipient } & \multicolumn{1}{c}{ Procedure } \\
\hline Sex & Sex & Year of transplant \\
Age & Age & Ischemic time \\
Ethnicity & Ethnicity & \\
$\begin{array}{c}\text { Mechanism } \\
\text { of death }\end{array}$ & Diagnosis & \\
Blood type & Retransplantation & \\
Clinical & ECM0* \\
infection & Mechanical ventilation* \\
& Inotropic medication* \\
& Elevated creatinine* & \\
& PRA & \\
& Blood type \\
& Clinical infection* & \\
\hline
\end{tabular}

ECMO, Extracorporeal membrane oxygenation; $P R A$, panel-reactive antibody. *At time of transplantation.

\section{Methods}

This study was approved by the institutional review board of Children's Healthcare of Atlanta. Data for this analysis were supplied by UNOS. The data set consisted of the Transplant Candidate Registration form, the Transplant Recipient Registration form, and the Transplant Recipient follow-up form. The follow-up form was administered at repeated intervals. The purpose of the study was to assess the impact of retransplantation on patient survival and to examine recipient and donor-related factors (Table 1) that might influence outcome.

\section{Study Population}

This study included all patients younger than 18 years who underwent cardiac transplantation between May 1987 and December 2004. A total of 4227 heart transplants were performed; of these, 219 were retransplants. Subjects undergoing combined heart and lung transplantation were not included in this analysis.

\section{Statistical Analysis}

Data are expressed as mean $\pm \mathrm{SD}$ or median and range as appropriate. Statistical analysis was performed by Fisher exact test, $\chi^{2}$ test, Wilcoxon rank sum test, and Student $t$ test. Kaplan-Meier survival curve estimates, log-rank tests to compare survival curves, and Cox proportional hazards model were performed to assess multivariate associations between risk factors and freedom from death. Analysis was performed with STATA version 6.0 (Stata Corporation, College Station, Tex). All $P$ values are 2 -sided, and confidence intervals are $95 \%$.

\section{Results}

Cardiac retransplantation was performed at a median age of 9.0 years. The mean interval from initial transplantation to retransplantation was $4.7 \pm 3.8$ years. The ethnic composition of those undergoing retransplantation was as follows: white $(\mathrm{n}=132)$, African American $(\mathrm{n}=50)$, Hispanic $(\mathrm{n}=$ $22)$, Asian $(\mathrm{n}=6)$, mixed $(\mathrm{n}=5)$, American Indian $(\mathrm{n}=$ $2)$, and other $(n=2)$. The indications for retransplantation
TABLE 2. Indications for retransplantation $(\mathbf{n}=\mathbf{2 1 9})$

\begin{tabular}{lrr}
\hline & No. & $\%$ \\
\hline Acute rejection & 19 & 9 \\
Hyperacute rejection & 7 & 3 \\
Coronary allograft vasculopathy & 111 & 51 \\
Chronic rejection & 16 & 7 \\
Nonspecific graft failure & 34 & 16 \\
Primary failure & 10 & 5 \\
Other & 22 & 10 \\
\hline
\end{tabular}

are shown in Table 2. The most common indication for retransplantation was coronary allograft vasculopathy (CAV), accounting for just more than half of the subjects. A significant number of children were also described as having nonspecific graft failure $(16 \%)$, which in some cases may also have represented CAV. There were 42 subjects (19\%) who underwent retransplantation for early primary graft failure (retransplantation within 180 days of primary transplantation). Reported causes of early primary graft failure were primary failure $(\mathrm{n}=10)$, hyperacute rejection $(\mathrm{n}=7)$, nonspecific graft failure $(\mathrm{n}=7)$, acute rejection $(\mathrm{n}=7), \operatorname{CAV}(\mathrm{n}=2)$, and other $(\mathrm{n}=9)$.

Patients undergoing retransplantation were more likely to be African American, older, female, allosensitized, and with elevated serum creatinine relative to primary transplant recipients (Table 3). Retransplant recipients had longer waiting times than primary transplant recipients. The median waiting time for retransplant recipients was 37 days.

Retransplantation was associated with poorer overall survival than primary transplantation. The 1-, 5-, and 10-year survivals after retransplantation were $79 \%, 53 \%$, and $44 \%$, respectively. The 1-, 5-, and 10-year survivals after primary transplantation were $83 \%, 70 \%$, and $58 \%$, respectively (Figure 1). The survival half-life after retransplantation was 5.6 years, compared with 13.2 years after primary transplantation. When multivariate analysis was undertaken, retransplantation was identified as a significant risk factor for mortality (odds ratio $1.67,95 \%$ confidence interval 1.32 $2.12, P<.001)$. Other variables found to be associated with lower survival were earlier year of transplantation, female sex, African American ethnicity, mechanical ventilation at time of transplantation, congenital heart disease, and older donor age (Table 4). The causes of death after retransplantation were as follows: acute rejection (14\%), CAV (14\%), infections $(13 \%)$, nonspecific graft failure (8\%), pulmonary disease $(7 \%)$, primary graft failure $(5 \%)$, chronic rejection $(5 \%)$, multiorgan failure $(5 \%)$, cerebrovascular disease $(3 \%)$, and all other causes $(26 \%)$.

We subsequently attempted to identify factors associated with poorer outcome among those subjects who underwent retransplantation. Year of transplantation, need for extracorporeal membrane oxygenation, recipient ethnicity, recipient 
TABLE 3. Patient characteristics

\begin{tabular}{|c|c|c|c|}
\hline & $\begin{array}{l}\text { Retransplantation } \\
\quad(\mathrm{n}=219)\end{array}$ & $\begin{array}{l}\text { Primary transplantation } \\
\qquad(\mathrm{n}=4008)\end{array}$ & $P$ value \\
\hline Median age at transplantation (y) & $9(0-17)$ & $3(0-17)$ & .001 \\
\hline Female recipient (No.) & $113(51.5 \%)$ & $1713(42.7 \%)$ & .01 \\
\hline African American recipient (No.) & $50(22.8 \%)$ & $667(16.6 \%)$ & .02 \\
\hline Inotropic medication (No.)* & $84(38.3 \%)$ & $1559(38.9 \%)$ & .86 \\
\hline UNOS status 2 (No.)* & $62(29.5 \%)$ & $1111(27.8 \%)$ & .98 \\
\hline Elevated serum creatinine $\left(\mathrm{No}_{0}\right)^{*}$ & $16(8.5 \%)$ & $87(3.3 \%)$ & .001 \\
\hline Mechanical ventilation (No.)* & $53(24.2 \%)$ & $787(19.6 \%)$ & .10 \\
\hline Extracorporeal membrane oxygenation (No.)* & $14(6.4 \%)$ & $181(4.5 \%)$ & .26 \\
\hline PRA $\geq 20 \%$ (No.) & $45(23.6 \%)$ & $228(6.9 \%)$ & $<.001$ \\
\hline Time on waiting list (d) & $37(1-1218)$ & $29(1-1842)$ & .04 \\
\hline
\end{tabular}

UNOS, United Network for Organ Sharing; PRA, Panel-reactive antibody. *At time of transplantation. $†$ Serum creatinine $\geq 2 \mathrm{mg} / \mathrm{dL}$.

sex, and age of donor were not associated with survival after retransplantation. Rather, the need for mechanical ventilation at time of retransplantation and early primary graft failure (retransplantation within 180 days of initial transplant) were identified as risk factors for mortality $(P<.03$ and $P<.02$, respectively). The 1-year survival for those with early primary graft failure was only $53 \%$, compared with $86 \%$ for those who had late primary graft failure (Figure 2). After exclusion of those with early primary graft failure, the 1-year survival for retransplantation did not differ from that of primary transplantation (86\% vs. $83 \%$, respectively). However, by 5 years the survival was significantly worse for the retransplant recipients with late primary graft failure compared than for primary transplant recipients $(55 \%$ vs $70 \%, P<.001)$.

\section{Discussion}

To date, more than 4000 children have undergone heart transplantation in the United States. ${ }^{1}$ Intermediate-term survival has improved considerably, although the survival half-

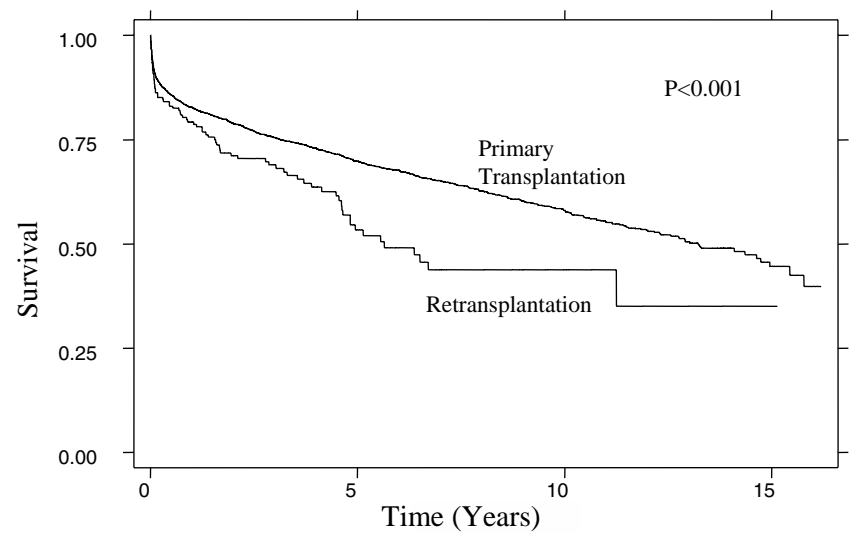

Figure 1. Kaplan-Meier survival plot after transplantation stratified by primary transplantation $(n=4008)$ versus retransplantation $(\mathrm{n}=219)$. life in children is less than 13 years. ${ }^{1}$ Retransplantation is considered a reasonable alternative for these children. This study, however, suggests that survival after retransplantation in children is significantly worse than that after primary cardiac transplantation.

A number of institutions have reported promising results fttlor pediatric retransplantation. Dearani and colleagues ${ }^{4}$ reported that the 3-year survival for children undergoing retransplantation was $82 \%$ and was not significantly different from that of those undergoing primary retransplantation (77\%). From our own institution, we reported that 3-year survivals were also similar between retransplantation and primary transplantation $\left(78 \%\right.$ vs $73 \%$, respectively). ${ }^{3}$ Equivalent survivals in the two groups were noted even though the retransplant recipients were more likely to be UNOS status 1 and to be cared for in the intensive care unit. In an earlier study, Michler and colleagues ${ }^{5}$ reported a 3 -year survival of $47 \%$ in a cohort of 17 children undergoing retransplantation. In this series as well, the mean graft survival for retransplantation was similar to that of primary transplantation. Conversely, in a recent analysis of the International Society for Heart and Lung Transplantation data

TABLE 4. Risk factors for death after transplantation $(n=$ 4227)

\begin{tabular}{lcrr}
\hline Variable & $\begin{array}{c}\text { Hazard } \\
\text { ratio }\end{array}$ & $\begin{array}{c}\text { 95\% Confidence } \\
\text { interval }\end{array}$ & $\begin{array}{c}\boldsymbol{P} \\
\text { value }\end{array}$ \\
\hline Retransplantation & 1.67 & $1.32-2.12$ & $<.001$ \\
Female recipient & 1.18 & $1.06-1.32$ & .003 \\
Later year of transplant & 0.96 & $0.95-0.98$ & $<.001$ \\
$\begin{array}{l}\text { Extracorporeal membrane } \\
\quad \text { oxygenation* }\end{array}$ & 1.92 & $1.50-2.48$ & $<.001$ \\
Mechanical ventilation* & 1.30 & $1.13-1.50$ & $<.001$ \\
African American recipient & 1.65 & $1.44-1.89$ & $<.001$ \\
Congenital heart disease & 1.32 & $1.18-1.50$ & $<.001$ \\
Older donor age (effect/year) & 1.009 & $1.004-1.01$ & $<.001$ \\
\hline
\end{tabular}

*At the time of transplantation. 


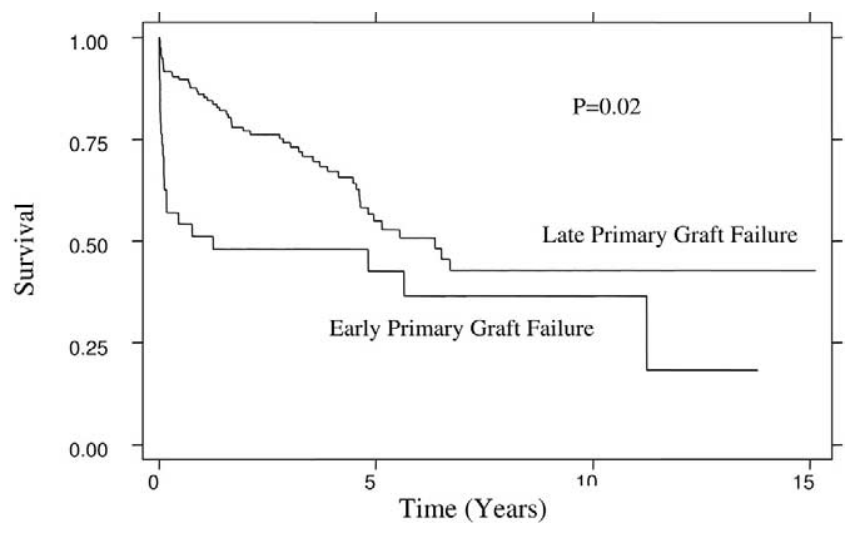

Figure 2. Kaplan-Meier survival plot for patients undergoing retransplantation ( $n=219$ ) stratified by early $(<180$ days from initial transplantation) or late ( $>180$ days from initial transplantation) primary graft failure.

set from 1996 to 2001, Boucek and colleagues ${ }^{1}$ found that retransplantation was associated with lower 1-year survival but was not identified as a risk factor for decreased 5-year survival. In our study spanning more than 15 years of UNOS data, we found retransplantation to be associated with significantly lower survival. The 5-year survival for retransplantation was just greater than $50 \%$. The median survival after retransplantation was only 5.6 years. The relatively large patient population and longer follow-up allowed us to identify differences in survival for the retransplant recipients that had not been identified in smaller, single-center series.

Shorter time from primary heart transplantation to graft failure was associated with poorer outcome after retransplantation. Just more than half of the subjects with early primary graft failure who underwent retransplantation were alive at 1 year, compared with $86 \%$ for those undergoing retransplantation for late graft failure. A similar association was noted in adults in an analyses of the Cardiac Transplant Research Database and the International Society of Heart Lung Transplantation. ${ }^{6,7}$ Radovancevic and colleagues ${ }^{6}$ reported that 1 -year survival was less than $50 \%$ when retransplantation was performed within 6 months of primary transplantation. The poorer outcome of children and adults who undergo retransplantation within 6 months of previous transplantation is probably related to significant pretransplantation morbidity and may reflect the need to accept a suboptimal donor organ. In light of the relatively poor outcome of children undergoing retransplantation for early primary graft failure, the appropriateness of relisting in this setting needs to be questioned. Some institutions have adopted of policy limiting retransplantation only to those patients with late primary graft failure. John and colleagues ${ }^{8}$ have reported survival greater than $90 \%$ in adults undergoing retransplantation for late graft failure. Radovancevic and colleagues ${ }^{6}$ have suggested that retransplantation for CAV may be a reasonable approach in adult patients, especially when one considers improvements in the management of CAV in recent years.

Even after exclusion of children undergoing retransplantation for early primary graft failure, the overall survival for retransplantation was still significantly less than that for primary transplantation. The 5-year survival of patients undergoing retransplantation for late primary graft failure with indications such as CAV or late nonspecific graft failure was only $55 \%$, significantly less than that of patients undergoing primary transplantation during the same era $(70 \%)$. The reasons for poorer survival after retransplantation may be manifold. Children listed for retransplantation are more likely to be allosensitized. ${ }^{3}$ More than $20 \%$ of retransplant recipients in this series had pretransplantation panel-reactive antibody (PRAttttl) level greater than 20\%. Although our analysis did not find high PRA to be associated with mortality, a recent report from the Pediatric Heart Transplant Study Group demonstrated that elevated pretransplantation PRA was associated with lower survival and shorter time to first rejection. ${ }^{9}$ In addition, other poorly defined immunologic factors that may have predisposed toward initial graft loss could lead to the loss of the retransplanted graft. Finally, social and environmental factors, such as medication noncompliance, might be more common among patients who undergo retransplantation. ${ }^{10}$

An extensive number of recipient and donor factors that affect survival after pediatric heart transplantation have been identified. These risk factors include recipient congenital heart disease, recipient elevated PRA, recipient African American ethnicity, and donor factors such as older age. ${ }^{1,11}$ Because of the relatively small number of children who underwent retransplantation, analysis of potential risk factors within this subgroup of retransplant recipients was limited. We did find that pretransplantation mechanical ventilation was associated with poorer survival. Unlike studies of adults undergoing retransplantation, we did not find that later year of retransplantation was associated with improved survival. ${ }^{6}$ It remains to be seen whether improvements in immunosuppression will result in improved retransplantation outcomes in coming years.

Given that graft survival after retransplantation is inferior to that after primary transplantation, questions as to the appropriateness of retransplantation arise. ${ }^{12}$ Although waiting times for pediatric heart transplants are less than for adults, donor organ availability remains a concern. The competition for such organs may increase in coming years, because the increased number of pediatric heart transplants in the early 1990s is likely to result in an increased number of children, adolescents, and young adults who would be candidates for retransplantation. It is possible that listing for retransplantation might be deferred in some cases, particu- 
larly children with CAV. Initial reports suggested that the outcome for children diagnosed with CAV was quite poor and that retransplantation would offer the best chance for survival. ${ }^{13}$ Recent reports, however, have suggested improved outcomes once CAV is recognized in children. ${ }^{14}$ In addition, agents such as sirolimus and the use of coronary artery stenting may offer an option to halt or reverse the progression of CAV. ${ }^{15-18}$ Given these findings and the stated limitations of retransplantation, medical interventions may offer an alternative to or a means of delaying the need for retransplantation for subjects in whom CAV develops.

In summary, retransplantation results in reasonable survival for children, although outcomes are inferior to those of primary transplantation. When retransplantation is performed in the setting of early primary graft failure, the results are quite poor, and the appropriateness of this strategy is questionable in light of the limited donor supply. Further data regarding the natural history of CAV and nonspecific graft failure will help in understanding the risks and benefits of retransplantation in children.

We thank Ms Cynthia S. Cors from the UNOS Research Department for assisting in data preparation.

\section{References}

1. Boucek MM, Edwards LB, Keck BM, Trulock EP, Taylor DO, Hertz MI. Registry for the International Society for Heart and Lung Transplantation: seventh official pediatric report-2004. J Heart Lung Transplant. 2004;23:933-47.

2. Morrow WR, Frazier E, Naftel DC. Survival after listing for cardiac transplantation in children. Prog Pediatr Cardiol. 2000;11:99-105.

3. Kanter KR, Vincent RN, Berg AM, Mahle WT, Forbess JM, Kirshbom PM. Cardiac retransplantation in children. Ann Thorac Surg. 2004;78: 644-9.

4. Dearani JA, Razzouk AJ, Gundry SR, Chinnock RE, Larsen RL, del Rio MJ, et al. Pediatric cardiac retransplantation: intermediate-term results. Ann Thorac Surg. 2001;71:66-70.
5. Michler RE, Edwards NM, Hsu D, Bernstein D, Fricker FJ, Miller J, et al. Pediatric retransplantation. J Heart Lung Transplant. 1993;12(6 Pt 2):S319-27.

6. Radovancevic B, McGiffin DC, Kobashigawa JA, Cintron GB, Mullen GM, Pitts DE, et al. Retransplantation in 7,290 primary transplant patients: a 10-year multi-institutional study. J Heart Lung Transplant. 2003;22:862-8.

7. Srivastava R, Keck BM, Bennett LE, Hosenpud JD. The results of cardiac retransplantation: an analysis of the Joint International Society for Heart and Lung Transplantation/United Network for Organ Sharing Thoracic Registry. Transplantation. 2000;70:606-12.

8. John R, Chen JM, Weinberg A, Oz MC, Mancini D, Itescu S, et al. Long-term survival after cardiac retransplantation: a twenty-year single-center experience. J Thorac Cardiovasc Surg. 1999;117:543-55.

9. Mahle WT, Naftel DC, Rusconi P, Edens R, Shaddy R. Panel-reactive antibody cross-reactivity and outcomes in the pediatric heart transplant study group. J Heart Lung Transplant. 2004;23 Suppl 2:S167.

10. Smith JA, Ribakove GH, Hunt SA, Miller J, Stinson EB, Oyer PE, et al. Heart retransplantation: the 25 -year experience at a single institution. J Heart Lung Transplant. 1995;14:832-9.

11. Pahl E, Naftel DC, Canter CE, Frazier EA, Kirklin JK, Morrow WR. Death after rejection with severe hemodynamic compromise in pediatric heart transplant recipients: a multi-institutional study. $J$ Heart Lung Transplant. 2001;20:279-87.

12. Meerdink P. Heart retransplantation: what is the right choice? Prog Cardiovasc Nurs. 2001;16:39-40.

13. Pahl E, Zales VR, Fricker FJ, Addonizio LJ. Posttransplant coronary artery disease in children. A multicenter national survey. Circulation. 1994;90(5 Pt 2):II56-60.

14. Pietra B, Boucek M. Coronary artery vasculopathy in pediatric cardiac transplant patients: the therapeutic potential of immunomodulators. Paediatr Drugs. 2003;5:513-24.

15. Doshi AA, Rogers J, Kern MJ, Hauptman PJ. Effectiveness of percutaneous coronary intervention in cardiac allograft vasculopathy. Am J Cardiol. 2004;93:90-2.

16. Wong PM, Piamsomboon C, Mathur A, Chastain HD, Singh DJ, Liu MW, et al. Efficacy of coronary stenting in the management of cardiac allograft vasculopathy. Am J Cardiol. 1998;82:239-41.

17. SoRelle R. Rapamycin slows heart transplant vasculopathy. Circulation. 2003;108:e9001.

18. Ruygrok PN, Webber B, Faddy S, Muller DW, Keogh A. Angiographic regression of cardiac allograft vasculopathy after introducing sirolimus immunosuppression. J Heart Lung Transplant. 2003;22: 1276-9. 